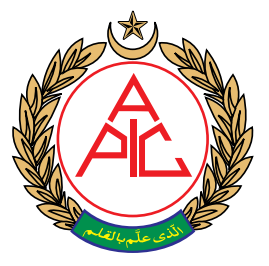

\title{
Comparison between intrathecal nalbuphine and butorphanol as adjuvants to isobaric ropivacaine in elective lower limb orthopedic surgeries: A prospective, randomized, double blind study
}

\author{
Akash Nirmal, Yashpal Singh, Sharad Kumar Mathur, Satish Patel
}

Department of Anesthesiology, Institute of Medical

Sciences, Banaras Hindu

University (IMS- BHU), Varanasi

22005. (India)

Akash Nirmal [talkwithakash@

yahoo.com]

Yashpal Singh

[dryashacin1999@rediffmail.

com]

Sharad Kumar Mathur

[skmathurbhu@gmail.com]

Satish Patel [doc.satish.patel@

gmail.com]

Correspondence: Dr Yashpal

Singh,

Dept. of Anesthesiology,

Institute of Medical

Sciences, Banaras Hindu

University (IMS- BHU),

Varanasi-221005, UP, (India);

E-mail: dryashacin1999@

rediffmail.com;

Phone: +919918424416

Received: 22 August 2019;

Reviewed: 8, 9 October 2019; 6 ,

7 November 2019;

Revised: 18 November 2019;

Reviewed: 19 November 2019;

Accepted: 20 November 2019

\section{ABSTRACT}

Background: Intrathecal ropivacaine is now routinely used for lower limb surgery. Adjuvants e.g. fentanyl, dexmedetomidine or morphine etc. are commonly used to prolong the intraoperative anesthesia or postoperative analgesia. The available literature lacks information on use of butorphanol and nalbuphine as adjuvants with $0.75 \%$ isobaric ropivacaine. We aimed to compare nalbuphine and butorphanol as adjuvant with isobaric ropivacaine in lower limb orthopedic surgeries.

Methodology: After institutional ethical committee approval and informed written consent, a total of 108 patients of ages between 18 to $65 \mathrm{y}$, of either sex, American Society of Anesthesiologists (ASA) grade I \& II, scheduled for elective lower limb orthopedic surgeries, were enrolled and randomly allocated into two groups: Group $\mathrm{RN}$; to receive isobaric ropivacaine $(0.75 \%, 7.5 \mathrm{mg} / \mathrm{ml}) 2.5 \mathrm{ml}$ plus nalbuphine $500 \mu \mathrm{g}$ $(0.5 \mathrm{ml})$, and Group RB; to receive isobaric ropivacaine $2.5 \mathrm{ml}$ plus butorphanol $100 \mu \mathrm{g}$ $(0.5 \mathrm{ml})$ intrathecally. Primary outcome measure was the duration of sensory-motor blockade from the time of intrathecal drug administration. Statistical analysis was performed by using t-test and chi-square test as applicable. A $p<0.05$ was considered as significant.

Results: Duration of sensory $(p<0.001)$ and motor blockade $(p=0.02)$ was significantly prolonged in nalbuphine group than butorphanol group. Onset of blockade was earlier in nalbuphine group. Duration of motor block and sensory analgesia was prolonged in group RN $(p<0.001)$. Perioperative hemodynamic parameters and the observed side effects including bradycardia, hypotension, nausea and vomiting, sedation and shivering were comparable between the two groups $(p=0.77)$.

Conclusion: Intrathecal nalbuphine produces prolonged motor blockade as well as postoperative analgesia than intrathecal butorphanol when used as adjuvants to isobaric $0.75 \%$ ropivacaine.

Citation: Nirmal A, Singh Y, Mathur SK, Patel S. Comparison between intrathecal nalbuphine and butorphanol as adjuvants to isobaric ropivacaine in elective lower limb orthopedic surgeries: A prospective, randomized, double blind study. Anaesth pain \& intensive care 2019;23(4):382-386. DOI: 10.35975/apic.v23i4.1171

\section{INTRODUCTION}

With advancement in drugs and technique, spinal anesthesia is now gold standard in lower limb orthopedic surgery. Various studies have clearly demonstrated advantage of neuraxial anesthesia 
in term of significant reduction in mortality and morbidity in comparison to general anesthesia. ${ }^{1}$ For the last many years local anesthetic (LA) bupivacaine has been used for spinal anesthesia due to its intense block characteristics. Now-a-days, bupivacaine is slowly being replaced by newer LA including ropivacaine in lower limb and lower abdominal surgeries. ${ }^{2-5}$ Ropivacaine is a long acting amide LA, structurally very similar to other pipecoloxylidides, first synthesized by Ekenstam. ${ }^{6}$ It is a pure s-enantiomer having less motor blockade and reduced cardiotoxicity which favors its attractiveness.

Various adjuvants have been tried to improve efficacy, duration of action and safety of LAs, but opioids are the most desired due to its prolonged analgesic action. Fentanyl, morphine, buprenorphine, butorphanol, midazolam, clonidine and dexmedetomidine have been used as adjuvants. ${ }^{7,8}$ Nalbuphine is an opioid, potent analgesic, structurally related to oxymorphone. It is highly lipid soluble with agonist action at $\kappa$-receptor and an antagonist activity at $\mu$-receptor. There have been studies of neuraxial administration of nalbuphine, shown to produce significant analgesia with minimal respiratory depression. ${ }^{9,10}$ There were safety issues regarding intrathecal uses of nalbuphine; however none of the abnormalities had been encountered through all these years and it was found to be safe for neuraxial blockade. Butorphanol is morphine type synthetic opioid analgesic and structurally related to levorphanol. It acts as an agonist on $\kappa$ and mixed agonistantagonist action at $\mu$-opioid receptors. It has been shown to improve the analgesic duration of LA and helps in decreasing analgesic utilization. ${ }^{11-12}$

Review of literature on nalbuphine and butorphanol with isobaric ropivacaine in adult patients is scarce. So we planned this study to compare nalbuphine and butorphanol with intrathecal isobaric ropivacaine in elective lower limb orthopedic surgeries. Primary outcome of our study was a comparison of block characteristics and duration of postoperative analgesia. Secondary outcomes includes comparison of hemodynamic parameters and adverse events, if any.

\section{METHODOLOGY}

After institutional ethical approval and written informed consent, this prospective, randomized, double blind, interventional clinical study was conducted at SS Hospital and Trauma Centre, Institute of Medical Sciences, Banaras Hindu University (IMS-BHU) Varanasi, during academic year 2015-17. Patients with a history of hypersensitivity to study drugs, general contraindications to spinal anesthesia, morbid obesity and end organ damage were excluded.

A total of 108 patients of ages between 18 to $65 \mathrm{y}$, of either sex, American Society of Anesthesiologists (ASA) grade $1 \& 11$. scheduled for elective lower limb

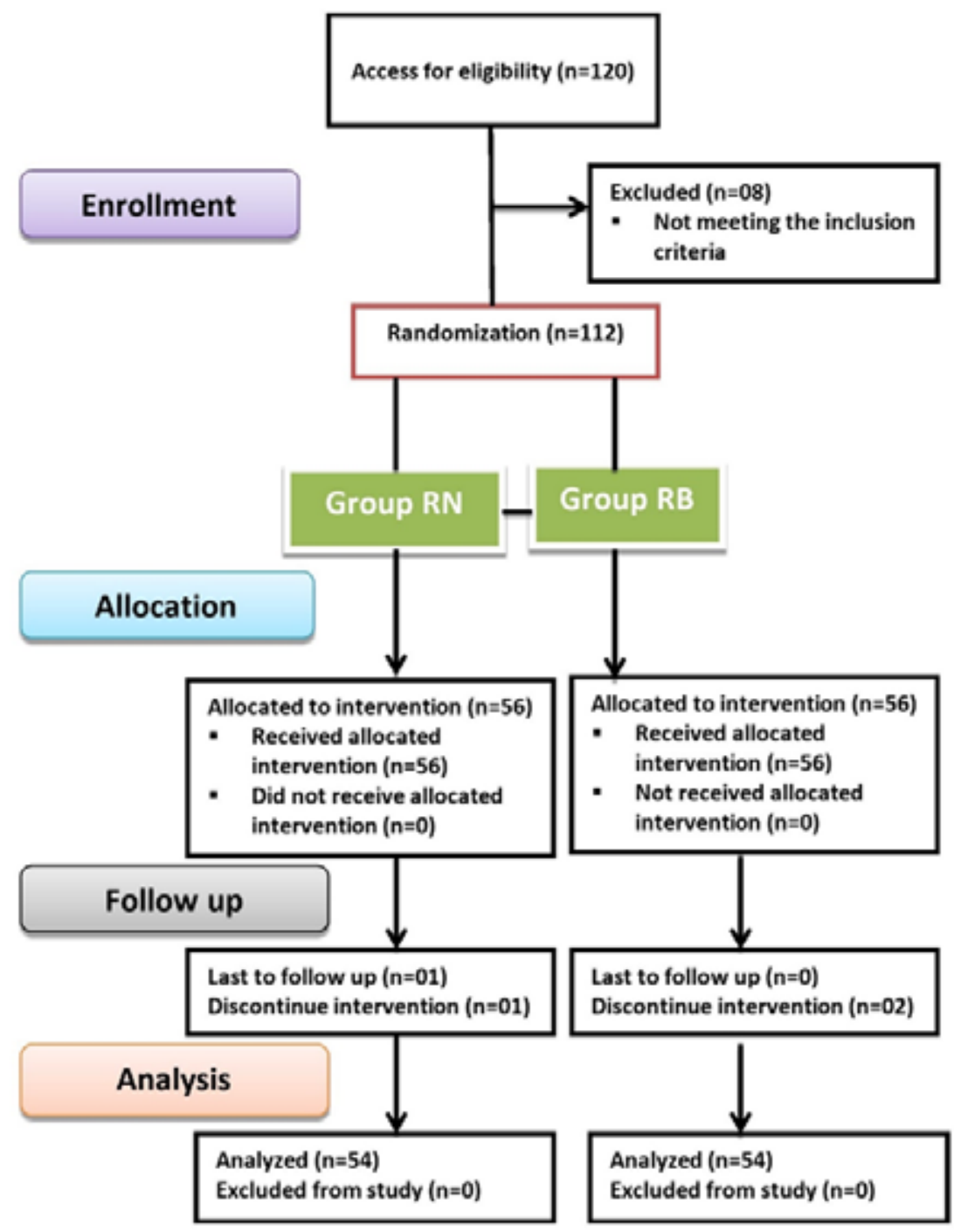

Figure 1: Flow chart of patient studied 
Table 1: Comparison of demographic data and baseline parameters between two Primary outcome measure groups $[$ mean \pm SD]

\begin{tabular}{|c|c|c|c|c|}
\hline \multicolumn{2}{|c|}{ Parameters } & Group RN & Group RB & p value \\
\hline \multicolumn{2}{|l|}{ Age } & $39.25 \pm 15.06$ & $38.33 \pm 14.92$ & 0.85 \\
\hline \multicolumn{2}{|c|}{ Weight } & $61.48 \pm 7.64$ & $62.54 \pm 6.00$ & 0.43 \\
\hline \multirow{2}{*}{ Sex } & Male (n) & 14 & 16 & \multirow{2}{*}{0.85} \\
\hline & Female (n) & 38 & 40 & \\
\hline \multicolumn{2}{|c|}{ Baseline HR } & $77.96 \pm 4.024$ & $79.11 \pm 5.83$ & 0.24 \\
\hline \multicolumn{2}{|c|}{ Baseline NIBP } & $112.58 \pm 10.30$ & $113.66 \pm 10.18$ & 0.58 \\
\hline
\end{tabular}

$H R=$ Heart Rate; $N I B P=$ Non-invasive mean blood pressure

Table 2: Comparison of block characteristics and post op analgesia between two groups $[$ mean $\pm \mathrm{SD}]$

\begin{tabular}{l|c|c|c}
\multicolumn{1}{c|}{ Parameters } & Group RN & Group RB & p value \\
\hline Time of onset of sensory block & $3.07 \pm 1.06$ & $3.79 \pm 0.95$ & $<0.001$ \\
\hline Time of onset of motor block & $6.37 \pm 1.73$ & $7.06 \pm 1.31$ & 0.02 \\
\hline Highest level of sensory block & T6-T7 & T6-T7 & \\
\hline Duration of motor block & $226.63 \pm 32.48$ & $202.23 \pm 22.58$ & $<0.001$ \\
\hline Duration of sensory analgesia & $394.62 \pm 31.23$ & $316.61 \pm 28.81$ & $<0.001$ \\
\hline
\end{tabular}

was the duration of sensory-motor blockade from the time of intrathecal drug administration. Sensory level was assessed by pin prick method bilaterally in midclavicular line from T10. Modified Bromage scale was used to assess motor blockade. After spinal anesthesia, block assessment was done every 2 min until T10 dermatomal level and Bromage score of ' 3 ' was achieved. After it assessment was done every $20 \mathrm{~min}$ till recovery of S2 dermatome (duration of the sensory block) and cessation of motor block. Secondary outcomes included comparison of hemodynamic parameters and adverse events if any. Hemodynamic instability was managed by a protocol including fluid administration, inj. mephentermine $5 \mathrm{mg}$ bolus or inj. atropine $0.6 \mathrm{mg} \mathrm{IV}$ stat as required.

Descriptive statistics such as mean, median, range etc. were calculated for the study outcomes. Statistical comparison was made by applying sample t-test and chi-square test as applicable. A p $<0.05$ was considered significant.

orthopedic surgeries, were randomly allocated into two groups: Group RN; to receive isobaric ropivacaine $(0.75 \%, 7.5 \mathrm{mg} / \mathrm{ml}) 2.5 \mathrm{ml}$ plus nalbuphine $500 \mu \mathrm{g}(0.5$ $\mathrm{ml}$ ), and Group $\mathrm{RB}$; to receive isobaric ropivacaine $2.5 \mathrm{ml}$ plus butorphanol $100 \mu \mathrm{g}(0.5 \mathrm{ml})$ intrathecally. Randomization was performed by an anesthesiologist involved in studied drug preparation. Further procedure and the monitoring were performed by another investigator unaware of group allocation. Patients were also blinded to the drug regimen utilized for spinal anesthesia. In the sitting position under standard aseptic precautions, lumbar puncture was performed at L3-L4 intervertebral space in midline approach by 25 gauge Quincke spinal needle. The studied drug solution was injected over a period of 10-15 sec after the confirmation of free flow of CSF and patients were turned to the supine position.

\section{RESULTS}

Out of 120 patients, 108 completed study successfully (Figure 1). Demographic profile and baseline hemodynamic parameters were comparable between two groups (Table 1).

Time of onset of sensory and motor block was earlier in group $\mathrm{RN}$ than group $\mathrm{RB}$ and this was significant between two groups $(\mathrm{p}<0.05)$ (Table 2$)$. Time required to reach median maximum height of sensory block was comparable between two groups (Table 2).

Duration of sensory analgesia (The time required for sensory regression to S2 level) was significantly higher in group $\mathrm{RN}$ than group $\mathrm{RB}$ (394.62 \pm 31.23 vs. $316.61 \pm 28.81 \mathrm{~min})(\mathrm{p}<0.001)$ (Table 2$)$. Duration of motor block was more in group RN than 
group $\mathrm{RB}(226.63 \pm 32.48$ vs. $202.23 \pm 22.58 \mathrm{~min})$ and this was highly significant between two groups $(\mathrm{p}<0.001)$ (Table 2).

Intra-operative and postoperative hemodynamic parameters were comparable between two groups. Observed side effects included bradycardia, hypotension, nausea and vomiting, sedation and shivering were comparable between the two groups (Table 3).

\section{DISCUSSION}

Ropivacaine is a new long acting amide LA with lower risk of systemic and cardiotoxicity than bupivacaine. We conducted this trial to study the comparative efficacy of ropivacaine plus two of the adjuvants for major orthopedic lower limb surgeries as an alternative to bupivacaine. The use of adjuvants improves the intraoperative quality of anesthesia and postoperative analgesia. Studies have shown that intrathecal opioids can greatly enhance analgesia of sub-therapeutic doses of LA. We added nalbuphine and butorphanol to respective groups with ropivacaine to find out the duration of sensory analgesia and motor blockade. These drugs possess numerous pharmacologic similarities. They are both agonists of the kappa opioid receptor and partial agonists of the mu receptor. Both are equianalgesic (and nalbuphine is equipotent) with morphine parenterally and codeine orally.

Mean time of onset of sensory and motor block was significantly lower in nalbuphine group than butorphanol group. This is supported by study done by Fournier et al. ${ }^{13}$ They studied analgesic effects of intrathecal morphine $160 \mu \mathrm{g}$ and nalbuphine $400 \mu \mathrm{g}$ in geriatric patients scheduled for elective total hip replacement under continuous spinal anesthesia, given in the postoperative period in the recovery room, and concluded that administration of intrathecal nalbuphine resulted in a significantly faster onset of pain relief.

Our study demonstrated that duration of analgesia, sensory and motor blockade is significantly prolonged in nalbuphine group (group $\mathrm{RN}$ ). In a randomized, double blind, controlled study done by Sapate et al. ${ }^{14}$ on adding intrathecal nalbuphine to bupivacaine for patients undergoing infraumblical surgeries, they concluded that intrathecal nalbuphine added to bupivacaine provided better quality of block and longer postoperative analgesia by $8-9 \mathrm{~h}$ than bupivacaine alone without any significant adverse effects. In a study by Tiwari et al. ${ }^{15}$ it was shown that addition of $0.4 \mathrm{mg}$ nalbuphine significantly prolongs the duration of sensory block and postoperative analgesia.

Brockway MS et al. ${ }^{16}$ conducted a study comparing $0.5 \%, 0.75 \%$ and $1 \%$ ropivacaine with $0.5 \%$ and $0.75 \%$ bupivacaine. They found the mean upper limit of sensory block was T6. The above studies concluded that the highest level of sensory block was similar between nalbuphine group and butorphanol group. These findings are similar to our study.

In our study use of $500 \mu \mathrm{g}$ nalbuphine and $100 \mu \mathrm{g}$ butorphanol with ropivacaine resulted in moderate hypotension, requiring inj. mephentermine in both the groups after the intrathecal drug administration. Although mephentermine requirement was slightly higher in the nalbuphine group ( 8 in RN vs. 4 in RB), but they were not statistically significant.

\section{LIMITATION}

Our study had few limitations. First, we did not assess the surgeons' or patients' satisfaction for intrathecal nalbuphine and butorphanol. Second, the results may vary between different ethnical groups of population due to disparity in weight, height and subjective anesthetic drug sensitivity.

\section{CONCLUSION}

Both nalbuphine and butorphanol produce good postoperative analgesia without any significant adverse side effects, when used as adjuvants to isobaric $0.75 \%$ ropivacaine for spinal anesthesia in lower limb surgeries. Intrathecal nalbuphine was associated with early onset of sensory and motor block and significantly prolonged postoperative analgesia as compared to butorphanol.

Conflict of interest: Nil declared by the authors

\section{Authors' contribution:}

All authors took equal part in concept and design of the study, conduct of study, data collection, literature search, manuscript preparation and editing. 


\section{REFERENCES}

1. Henderson V. Basic Principles of Nursing Care. Geneva: International Council of Nurses;1960.

2. Paju S, Scannapieco FA. Oral biofilms, periodontitis, and pulmonary infections. Oral Dis. 2007;13(6):50812. [PubMed] DOI: $10.1111 /$ i.16010825.2007.01410a.x

3. Ibrahim SM, Mudawi AM, Omer 0. Nurses' knowledge, attitude and practice of oral care for intensive care unit patients. Open J Stomat. 2015;5(7):179-86. DOI: 10.4236/ ojst.2015.57023

4. Faragalla Al, Almaki EJ, Asiri HA. Knowledge, attitude and practice of nurses to oral health care for hospitalized patients in Abha citySaudi Arabia. Acta Scientific Dental Sci. 2018;2(5):16-23. [Free Full Text]

5. Quinn B, MSN, RN, BC, Baker DL. Comprehensive oral care prevents hospital-acquired non-ventilator pneumonia. American Nurse Today. 2015;10(3):18-23. [Free Full Text]

6. Grap MJ, Munro CL, Ashtiani B, Bryant S. Oral care interventions in critical care: frequency and documentation. Am J Crit Care. 2003;12(2):113-99. [PubMed]

7. Hanneman SK, Gusick GM. Frequency of oral care and positioning of patients in critical care: A replication study. Am J Crit Care. 2005;14(5):378-87. [PubMed]

8. Costello T, Coyne I. Nurses' knowledge of mouth care practices. Br J Nurs. 2008;17(4):264-68. [PubMed] DOI: 10.12968/bjon.2008.17.4.28716

9. Wilkin K. A critical analysis of the philosophy, knowledge and theory underpinning mouth care practice for the intensive care unit patient. Intensive Crit Care Nurs. 2002;18(3):181-8. [PubMed] DOI: 10.1016/s0964397(02)00017-4

10. Soh KL, Shariff GS, Soh KG, Abdul RR, Sharif ASS, Ong SL. Oral care practice for the ventilated patients in intensive care units: a pilot survey. J Infect Dev Ctries. 2012;6(4):333-9. [PubMed]

11. Hajibagheri A, Azizi FI. Mouth care in patients receiving mechanical ventilation: a systematic review. Nurs Midwifery Stud. 2012;1(2):51-61. [Free Full Text]

12. Atay S, Karabacak, U. Oral care in patients on mechanical ventilation in intensive care unit: literature review. Int J Res Med Sci. 2014;2(3):822-9. [Free Full Text]

13. Robinson $P$, Deacon SA., Deery $C$, Heanue $M$, Walmsley $A D$, Worthington $\mathrm{HV}$, et al. Manual versus powered toothbrushing for oral health. Cochrane Database Syst Rev. 2005 Apr 18;(2):CD002281. [PubMed] DOI: 10.1002/14651858.CD002281.pub2

14. Miranda AF, de Paula RM, de Castro Piau CG, Costa PP, Bezerra AC. Oral care practices for patients in intensive care units: A pilot survey. Indian J Crit Care Med. 2016;20(5):26773. [PubMed] DOl: 10.4103/0972$\underline{5229.182203}$

15. Ozveren H, Ozden D. Turkish nurses' attitudes and practices regarding oral care. Int $\mathrm{J}$ Nurs Knowl. 2015;26(4):163-9. [PubMed] DOI: $\underline{10.1111 / 2047-3095.12060}$

16. Needleman IG, Hirsch NP, Leemans $M$, Moles DR, Wilson M, Ready DR, et al. Randomized controlled trial of toothbrushing to reduce ventilatorassociated pneumonia pathogens and dental plaque in a critical care unit. J Clin Periodontol. 2011;38(3):24652. [PubMed] DOI: $10.1111 / \mathrm{i} .1600$ 051X.2010.01688.X

17. Koeman $M$, van der Ven AJ, Hak $\mathrm{E}$, Joore $\mathrm{HC}$, Kaasjager $\mathrm{K}$, de Smet $A G$, et al. Oral decontamination with chlorhexidine reduces the incidence of ventilator-associated pneumonia. Am J Respir Crit Care Med. 2006;173(12):1348-55. [PubMed] DOI: $10.1164 / \mathrm{rccm} .200505-8200 \mathrm{C}$

18. Sona CS, Zack JE, Schallom ME, McSweeney $M$, McMullen $K$, Coopersmith CM, et al. The impact of a simple, low-cost oral care protocol on ventilator-associated pneumonia rates in a surgical intensive care unit. J Intensive Care Med. 2009; 24(1):54-62. [PubMed] DOI: $\underline{10.1177 / 0885066608326972}$
19. Tantipong $\mathrm{H}, \quad$ Morkchareonpong C, Jaiyindee S, Thamlikitkul V. Randomized controlled trial and metaanalysis of oral decontamination with $2 \%$ chlorhexidine solution for the prevention of ventilator-associated pneumonia. Infect Control Hosp Epidemiol. 2008;29(2):131-6. [PubMed] DOI: 10.1086/526438

20. Turk G, Kocacal Guler E, Eser I, Khorshid L. Oral care practices of intensive care nurses: A descriptive study. Int J Nurs Pract. 2012;18(4):347-53. [PubMed] DOl: 10.1111/j.1440-172X.2012.02045.X

21. DeKeyser Ganz F, Fink NF, Raanan 0 , Asher $M$, Bruttin $M$, Nun MB, et al. ICU nurses' oral-care practices and the current best evidence. J Nurs Scholarsh. 2009;41(2):1328. [PubMed] DOI: 10.1111/i.15475069.2009.01264.x

22. Bader MK, Littlejohns LR. AANN Core Curriculum for Neuroscience Nursing. Glenview, IL;2010.

23. Cutler CJ, Davis N. Improving oral care in patients receiving mechanical ventilation. $\mathrm{Am} J$ Crit Care. 2005;14(5):389-94. [PubMed]

24. Adib Hajbagheri M, Ansari A, Azizi-Fini I. Intensive care nurses' opinions and practice for oral care of mechanically ventilated pateints. Indian J Crit Care Med. 2013;17(1):23-7. [PubMed] DOI: $10.4103 / 0972-5229.112154$

25. Cason CL, Tyner T, Saunders S, Broome L. Nurses' implementation of guidelines for ventilator-associated pneumonia from the Centers for Disease Control and Prevention. Am J Crit Care. 2007;16(1):28-36. [PubMed]

26. Johnstone L, Spence D, KoziolMcClain J. Oral hygiene care in the pediatric intensive care unit: practice recommendations. Pediatr Nurs. 2010;36(2):85-96. [PubMed]

27. Terezhalmy GT, Bartizek RD, Biesbrock AR. Relative plaque removal of three toothbrushes in a nine-period crossover study. J Periodontol. 2005;76(12):2230-5. [PubMed] DOl: $\underline{10.1902 / j o p .2005 .76 .12 .2230}$ 